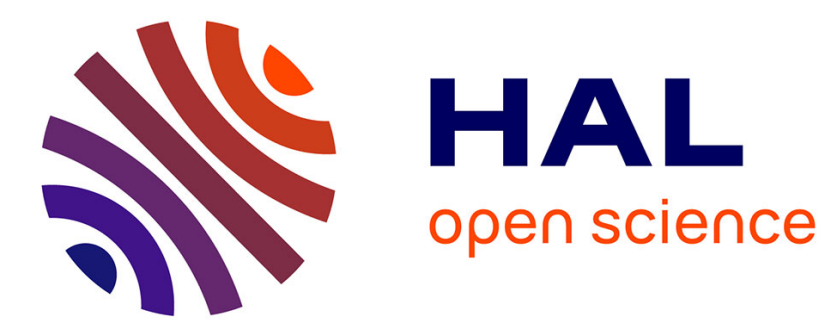

\title{
Metabolism of imidacloprid inApis mellifera
}

Séverine Suchail, Laurent Debrauwer, Luc Belzunces

\section{To cite this version:}

Séverine Suchail, Laurent Debrauwer, Luc Belzunces. Metabolism of imidacloprid inApis mellifera. Pest Management Science, 2004, 60 (3), pp.291-296. 10.1002/ps.772 . hal-02047806

\section{HAL Id: hal-02047806 \\ https://hal-univ-avignon.archives-ouvertes.fr/hal-02047806}

Submitted on 7 Mar 2019

HAL is a multi-disciplinary open access archive for the deposit and dissemination of scientific research documents, whether they are published or not. The documents may come from teaching and research institutions in France or abroad, or from public or private research centers.
L'archive ouverte pluridisciplinaire HAL, est destinée au dépôt et à la diffusion de documents scientifiques de niveau recherche, publiés ou non, émanant des établissements d'enseignement et de recherche français ou étrangers, des laboratoires publics ou privés. 


\title{
Metabolism of imidacloprid in Apis mellifera
}

\author{
Séverine Suchail, ${ }^{1 *}$ Laurent Debrauwer $^{2}$ and Luc P Belzunces ${ }^{1}$ \\ ${ }^{1}$ INRA, UMR 406 INRA-UAPV Ecologie des Invertébrés, Site Agroparc, 84914 Avignon Cedex 9, France \\ ${ }^{2}$ UMR INRA-ENVT-ENSAT INPT Xénobiotiques, 180 Chemin de Tournefeuille, Saint-Martin-du-Touch BP 3, 31931 Toulouse Cedex 9 , \\ France
}

\begin{abstract}
Biotransformation of imidacloprid and the appearance of olefin and 5-hydroxyimidacloprid metabolites in the honeybee were studied by HPLC-MS/MS analysis. Honeybees were treated orally with imidacloprid at 20 and $50 \mu \mathrm{g} \mathrm{kg}^{-1}$ bee. Imidacloprid was metabolised relatively quickly and thoroughly. Twenty minutes after the beginning of imidacloprid ingestion, the sum of the residues from the three compounds amounted to only $70 \%$ of the actual given dose. Imidacloprid, 5-hydroxyimidacloprid and olefin represented, respectively, $50 \%, 9 \%$ and $8 \%$ of the actual ingested dose. Six and $24 \mathrm{~h}$, respectively, after ingestion of imidacloprid at 20 and $50 \mu \mathrm{g} \mathrm{kg}^{-1}$ bee, imidacloprid could no longer be detected in the honeybee. Imidacloprid had a half-life ranging between 4.5 and $5 \mathrm{~h}$ and was rapidly metabolised into 5-hydroxyimidacloprid and olefin. Except 5-hydroxyimidacloprid in the $20 \mu \mathrm{g} \mathrm{kg}^{-1}$ treatment, these two metabolites presented a peak value $4 \mathrm{~h}$ after ingestion of the 20 and $50 \mu \mathrm{gg}^{-1}$ doses. This time fully coincided with the appearance of mortality induced by imidacloprid after acute oral intoxication. These results suggested that the immediate neurotoxicity symptoms are due to the action of imidacloprid, whereas 5-hydroxyimidacloprid and/or olefin are involved in honeybee mortality. In addition, it was likely that the $30 \%$ of residues undetected $20 \mathrm{~min}$ after intoxication were imidacloprid metabolites, although not 5-hydroxyimidacloprid or olefin. Thus, 5-hydroxyimidacloprid and olefin could not be the major metabolites in the worker bees.

(C) 2003 Society of Chemical Industry
\end{abstract}

Keywords: imidacloprid; metabolite; honeybee; metabolisation; LC-MS/MS

\section{INTRODUCTION}

Imidacloprid is a systemic insecticide that belongs to the neonicotinoid family. ${ }^{1}$ This active substance acts as a competitive agonist on the nicotinic acetylcholine receptor (nAChR) of insects. ${ }^{2,3}$ Imidacloprid is extremely effective against a wide variety of insects whereas it appears to be relatively non-toxic to vertebrates. ${ }^{4}$ This selective toxicity of all neonicotinoids is attributable, in general, to the specificity of insect and mammalian nicotinic receptors towards imidacloprid. ${ }^{5}$ In honeybee, imidacloprid exhibits a high toxicity. At $48 \mathrm{~h}$, oral and contact $\mathrm{LD}_{50}$ values are 5 and $25 \mathrm{ng}$ per bee, respectively. ${ }^{6}$ Studies on the acute toxicity of imidacloprid have revealed important characteristics. ${ }^{7}$ (1) After oral exposure, the dose-mortality relation presents a multi-phase profile with ascending and descending phases. (2) The kinetics of mortality are delayed as doses increase. These features suggest that metabolic pathways might be involved in imidacloprid toxicity. (3) Neurotoxicity symptoms appear rapidly, whereas mortality occurs $4 \mathrm{~h}$ after acute imidacloprid intoxication and is prolonged during more than $96 \mathrm{~h}$. Thus, imidacloprid has either a prolonged action or a delayed action, but the symptoms are always immediate. Chronic oral intoxication experiments have shown that imidacloprid induces mortality at concentrations of $0.1,1$ and $10 \mu \mathrm{g}$ litre $^{-1} .^{7}$ These results seem to contrast with those obtained by Schmuck et al ${ }^{8,9}$ who reported that exposure of bee colonies to sunflower honey containing imidacloprid at concentrations of 2, 5, 10 and $20 \mu \mathrm{g} \mathrm{kg}^{-1}$ does not induce any mortality or adverse effects on bee development. This discrepancy in results obtained in chronic toxicity studies may be due to the mode of administration used in the two studies and to the large variability in effects induced by imidacloprid, which depends on the bees and, for a given colony, on its physiological state. ${ }^{6}$

Of the six metabolites tested, only two, 5-hydroxyimidacloprid and an olefin (Fig 1), which are similar in chemical structure to imidacloprid, exhibit an acute toxicity close to that of the parent compound, with a higher toxicity for the latter and a lower toxicity for the former. ${ }^{7}$ Nauen et al ${ }^{10}$ reported similar results concerning the toxicity of 5-hydroxyimidacloprid and olefin to the honeybee.

* Correspondence to: Séverine Suchail, Laboratoire de Pollinisation Entomophile, UMR 406 INRA-UAPV, Ecologie des Invertébrés, Site Agroparc, 84914 Avignon Cedex 09, France

E-mail: suchail@avignon.inra.fr

Contract/grant sponsor: INRA

Contract/grant sponsor: Bayer France

(Received 26 September 2002; revised version received 9 April 2003; accepted 17 June 2003)

Published online 3 November 2003 
<smiles>O=[N+]([O-])/N=C1\NCCN1Cc1ccc(Cl)nc1</smiles>

Imidacloprid
5-Hydroxyimidacloprid<smiles>O=[N+]([O-])N=C1NCC(O)N1Cc1ccc(Cl)nc1</smiles><smiles>O=[N+]([O-])/N=c1\[nH]ccn1Cc1ccc(Cl)nc1</smiles>

Olefin

Figure 1. Chemical structures of imidacloprid, 5-hydroxyimidacloprid and olefin.

They showed further that dihydroxyimidacloprid also exhibits toxicity to bees. In other invertebrates, olefin is also highly toxic, being about ten times more active than imidacloprid against the cotton whitefly. ${ }^{11}$ In pest aphid species, olefin is more toxic than imidacloprid only when it is administrated by an oral route, when it is 16 times more active than imidacloprid. ${ }^{12}$ Nauen et $a l^{10}$ reported that the acute toxicity of 5 -hydroxyimidacloprid and olefin come from the existence of their nitroguanidine pharmacophore. Metabolites that do not carry this pharmacophore are not toxic to bees. In contrast, in 10-day chronic toxicity studies, all imidacloprid metabolites revealed equal toxicity to bees, but the total dose ingested by the bees was about 3000-100000 times lower than the doses needed to produce the same effect after acute intoxication. ${ }^{7}$ Toxicity such as that caused by imidacloprid has been already observed previously with other insecticides in honeybees. Fiedler ${ }^{13}$ has studied the chronic toxicity of organophosphorus insecticides to honeybees. For acephate, methamidophos and dimethoate, the cumulated dose resulting in a mortality of $50 \%$ was lower than the acute oral $\mathrm{LD}_{50}$ at $24 \mathrm{~h}$.

The discrepancy between the kinetics of mortality and the rapid appearance of neurotoxicity symptoms, together with the insecticidal activity of some metabolites after acute intoxication suggest a combined action of low amounts of toxic metabolites and imidacloprid. Nauen et $a l^{11}$ also suggest a concerted action between toxic metabolites and residues of imidacloprid to explain the long-term residual effectiveness of imidacloprid in plants. Thus, early neurotoxic symptoms could be elicited by imidacloprid itself whereas mortality could be induced by its toxic metabolites, ie 5-hydroxyimidacloprid and olefin, either alone or associated with imidacloprid at low residual amounts. This is in accordance with the action of imidacloprid on honeybee habituation, which is not only age- and dose-dependent but also time-dependent. ${ }^{14}$

To understand better the action of imidacloprid in the honeybee, we have studied the biotransformation of imidacloprid in bees after exposure to two doses close to the $\mathrm{LD}_{50}$. We focused on the two toxic metabolites, 5-hydroxyimidacloprid and the olefin, to discern a possible relationship between the occurrence of these metabolites and the appearance of honeybee mortality. An efficient analytical method was designed especially to determine the residues of these compounds in bees.

\section{MATERIALS AND METHODS \\ 2.1 Materials}

Imidacloprid [1-(6-chloro-3-pyridylmethyl)- $N$-nitroimidazolidin-2-ylideneamine] and its metabolites, 5hydroxyimidacloprid [1-(6-chloro-3-pyridylmethyl)5 -hydroxy- $N$-nitroimidazolidin-2-ylideneamine] and olefin [1-(6-chloro-3-pyridylmethyl)- $N$-nitro-4-imidazolin-2-ylideneamine] of analytical quality (98\% pure) were obtained from Bayer AG (Leverkusen, Germany).

For all bioassays, worker bees (Apis mellifera $\mathrm{L}$ ) were captured from honey and pollen combs in a healthy queen-right colony; all drones were discarded. To avoid inter-colony and seasonal variations, all bees were taken from the same colony. Immediately before treatment, bees were anaesthetised with carbon dioxide and kept in cages $(10.5 \times 7.5 \times 11.5 \mathrm{~cm})$ in a dark temperature-controlled chamber at $25( \pm 1.5)^{\circ} \mathrm{C}$ and $65( \pm 5) \%$ relative humidity. Bees were fed a $50 \%$ sucrose solution ad libitum. ${ }^{15}$ In each experiment, three cages of 20 bees were used for each dose of each treatment. Experiments were replicated at least three times.

\subsection{Oral application}

The honeybees were deprived of food for $2 \mathrm{~h}$ before administration of imidacloprid. A stock solution of imidacloprid was prepared in dimethyl sulfoxide (DMSO). This was diluted to the required concentration with DMSO, water and finally $500 \mathrm{~g} \mathrm{litre}^{-1}$ sucrose feeding solution so that the final DMSO concentration in the sucrose solutions for the assay and control tests was $1 \mathrm{ml}$ litre $^{-1}$. The dosing solutions were freshly prepared for each test. Two hundred microlitres of $500 \mathrm{~g} \mathrm{litre}^{-1}$ sucrose solution (vehicle) containing imidacloprid at concentrations of 0.5 or $0.2 \mathrm{ng} \mu \mathrm{l}^{-1}$ were given to groups of 20 bees, which corresponded to a mean individual volume of $10 \mu \mathrm{l}$ and to doses of 50 or $20 \mu \mathrm{g} \mathrm{kg}^{-1}$ bee (mean bee weight: $100 \mathrm{mg}$ ). Solutions containing $500 \mathrm{~g} \mathrm{litre}^{-1}$ sucrose alone were used as controls. In these experiments, bees completely consumed the test solutions. The $50 \mu \mathrm{g} \mathrm{kg}^{-1}$ dose represented the oral $\mathrm{LD}_{50}$ of imidacloprid in honeybee. The lower dose was also used to examine imidacloprid biotransformation. After consuming the solution containing imidacloprid or the control solution, bees were fed $500 \mathrm{~g} \mathrm{litre}^{-1}$ sucrose solution ad libitum. The metabolic study was performed only on live worker bees. Honeybees were killed by quick freezing at $-80^{\circ} \mathrm{C}$ in order to stop their metabolic activity abruptly at specific times: 0 , $4,6,24,30$ and $48 \mathrm{~h}$ after oral intoxication. Time 
0 corresponded to the end of total ingestion of the imidacloprid dose by honeybees, which took about $20 \mathrm{~min}$.

\subsection{Residue extraction from whole honeybees}

For each dose of each treatment, residues were extracted by grinding bees ( $2 \mathrm{~g}$, corresponding to 20 bees) in methanol + water ( $1+3$ by volume; $30 \mathrm{ml})$. Bee extract was supplemented with Celite (2g), filtered on a Büchner funnel and concentrated to an aqueous solution by removal of the methanol. For the determination of residues, the aqueous solution was partitioned against dichloromethane $(140 \mathrm{ml})$ using a ChemElut $^{\circledR}$ CE1020 column. The aqueous fraction was concentrated and redissolved in toluene + ethyl acetate $(2 \mathrm{ml} ; 85+15$ by volume). A second cleanup was performed on a $0.5 \mathrm{~g}$ silica gel column by elution with acetonitrile + water $(5 \mathrm{ml} ; 1000+1$ by

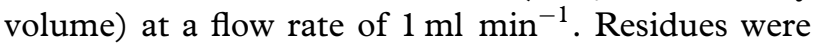
concentrated and dissolved in acetonitrile + water $(2+8$ by volume $)$. For recovery tests, honeybees $(2 \mathrm{~g})$ in methanol + water $(1+3$, by volume $)$ were fortified with a standard solution $\left(0.1 \mu \mathrm{g} \mathrm{ml}^{-1}\right)$ prepared in DMSO. The recovery rates were determined in fortification experiments in which defined amounts of imidacloprid, 5-hydroxyimidacloprid and olefin metabolites were added to control samples prior to extraction. Solutions containing imidacloprid, 5hydroxyimidacloprid and olefin were protected from light and stored at $4{ }^{\circ} \mathrm{C}$ in the dark during the entire procedure.

\subsection{HPLC-MS/MS analysis}

Fifty microlitres of residues were separated by reversed phase HPLC $\left(\mathrm{C}_{18}\right.$ column: $150 \times 4.5 \mathrm{~mm}$ ID; $5 \mu \mathrm{m}$ particle size) with electrospray MS/MS detection.

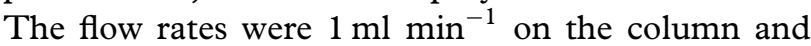
$0.15 \mathrm{ml} \mathrm{m^{-1 }}$ on the mass spectrometer. The mass spectrometer was tuned by infusing a standard solution of $0.5 \mathrm{mg}$ litre $^{-1}$ imidacloprid, 5-hydroxyimidacloprid and olefin (dissolved in acetonitrile + water $(2+8$ by volume) containing $0.1 \mathrm{ml}$ litre $^{-1}$ acetic acid) at a flow rate of $5-10 \mu \mathrm{lmin}^{-1}$. Details of the gradient for the HPLC-MS/MS measurement samples and the collision energies used were described by Schmuck et al. ${ }^{8}$ Residues were identified by their retention times and their $m / z$ ratios, where $m$ and $z$ represented the mass and the charge of the ion, respectively. All compounds were qualified with determination on the ${ }^{35} \mathrm{Cl}$ isotope and confirmation on the ${ }^{37} \mathrm{Cl}$ isotope. Residues were quantified by adding appropriate amounts of derivatives containing ${ }^{35} \mathrm{Cl}$ and ${ }^{37} \mathrm{Cl}$ isotopes. The limit of quantification of $0.5 \mu \mathrm{g} \mathrm{kg}^{-1}$ was achieved with a minimal signal-to-noise ratio of 3 .

\subsection{Imidacloprid half-life}

Half-life was determined by plotting $\ln \left(I / I_{\mathrm{o}}\right)$ against time according to the equation

$$
\ln \left(I / I_{\mathrm{o}}\right)=-k t
$$

where $I_{\mathrm{o}}$ and $I$ represent initial and residual imidacloprid concentrations. Half-life was calculated with the equation

$$
t_{1 / 2}=(\ln 2) / k
$$

where $t_{1 / 2}$ is the half-life and $k$ is the apparent elimination constant.

\section{RESULTS}

After oral ingestion of imidacloprid, early symptoms of poisoning included hyperactivity and tremors. After several hours, these symptoms gradually disappeared and the worker bees became hypoactive. After extraction, residues were separated by HPLC-MS/MS. The retention times of olefin, 5-hydroxyimidacloprid and imidacloprid were $4.5 \mathrm{~min}, 5.5 \mathrm{~min}$ and $9 \mathrm{~min}$, respectively. Samples were fortified with imidacloprid and its metabolites at $10 \mathrm{mg} \mathrm{kg}^{-1}$. Recovery (mean \pm SE) was about $98.6( \pm 4.1) \%$ for imidacloprid, $85.2( \pm 6.3) \%$ for 5-hydroxyimidacloprid and $78.9( \pm 11.9) \%$ for olefin.

The biodegradation of imidacloprid and the appearance of 5-hydroxyimidacloprid and olefin in honeybees were followed after oral application of imidacloprid at the doses of 50 or $20 \mu \mathrm{g} \mathrm{kg}^{-1}$ bee (Figs 2 and 3). The true doses administered to honeybees were 48.2 and $19.6 \mu \mathrm{g} \mathrm{kg}^{-1}$ bee and were determined by HPLC with UV detector set at $270 \mathrm{~nm}$.

Imidacloprid was metabolised relatively quickly and thoroughly. After total ingestion of $50 \mu \mathrm{g}$ imidacloprid $\mathrm{kg}^{-1}$ bee, the sum of imidacloprid, 5hydroxyimidacloprid and olefin residues represented $67 \%$ of the actual dose given. Imidacloprid, 5hydroxyimidacloprid and olefin represented respectively, $50 \%, 9 \%$ and $8 \%$ of the actual dose. After $6 \mathrm{~h}$, only $10.5 \%$ of imidacloprid were detected in honeybees and after $24 \mathrm{~h}$, it could not be detected. Imidacloprid had an elimination half-life of $4.5 \mathrm{~h}$ and was rapidly metabolised into 5-hydroxyimidacloprid and olefin. These two metabolites reached a peak value $4 \mathrm{~h}$ after oral intoxication. Olefin and 5hydroxyimidacloprid represented respectively, 9.5\% and $13 \%$ of the initial dose $4 \mathrm{~h}$ after intoxication. For both metabolites, the amount of residues started to decrease $4 \mathrm{~h}$ after exposure and represented approximately $5 \%$ of the ingested dose $48 \mathrm{~h}$ after exposure.

When the individuals were exposed to a dose of $20 \mu \mathrm{g}$ of imidacloprid per $\mathrm{kg}$ of bee, the metabolisation kinetics of imidacloprid were similar. Twenty minutes after total ingestion, imidacloprid represented $55 \%$ of the actual dose and after $6 \mathrm{~h}$ only $3 \%$ of residues were detected. The imidacloprid half-life was $5 \mathrm{~h}$ after intoxication with a dose of $20 \mu \mathrm{g} \mathrm{kg}^{-1}$ bee. Olefin metabolite presented a peak value $4 \mathrm{~h}$ after ingestion time at which time it represented $14 \%$ of the actual ingested dose. 5-Hydroxyimidacloprid had a different kinetic appearance. It appeared immediately during or after, the ingestion period 

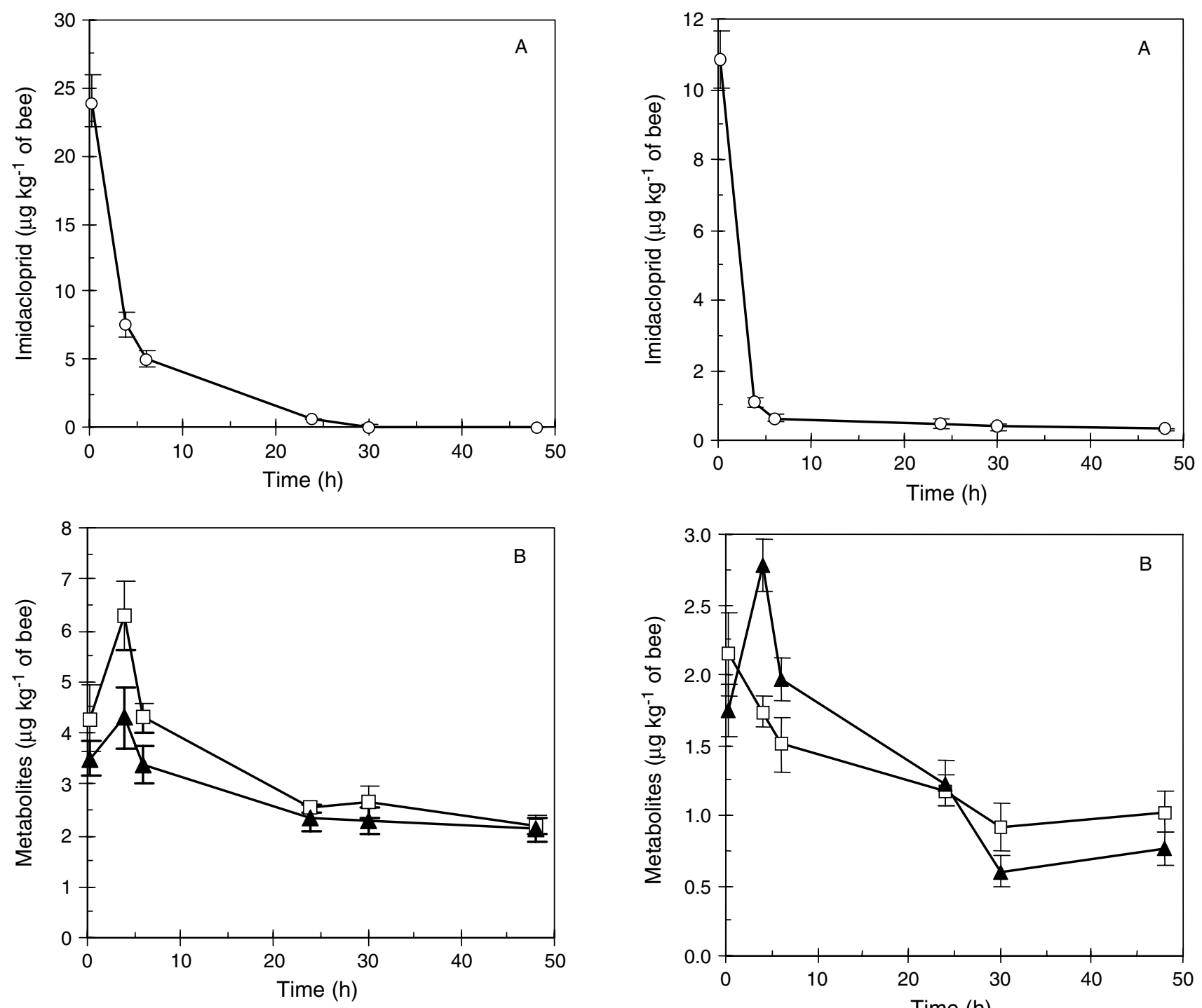

Figure 2. Biotransformation kinetics of imidacloprid after oral exposure to $50 \mu \mathrm{g} \mathrm{kg}^{-1}$ bee. A: Imidacloprid degradation. B: Appearance of $(\square)$ 5-hydroxyimidacloprid and $(\boldsymbol{\Delta})$ olefin. Data represent the means of three experiments performed in triplicate $\pm \mathrm{SD}$.

and, at the beginning of the biotransformation kinetics, represented about $11 \%$ of the initial dose. Both compounds decreased with time and, $4 \mathrm{~h}$ after intoxication, amounted to about $14.3 \%$ and $8.7 \%$ of the initial ingested dose for olefin and 5hydroxyimidacloprid, respectively.

\section{DISCUSSION}

Earlier toxicological studies of imidacloprid in the honeybee show a discrepancy between mortality kinetics and the rapid appearance of neurotoxicity symptoms. ${ }^{7}$ Moreover, neurotoxicity symptoms appeared within $10 \mathrm{~min}$ of intoxication, whereas 5-hydroxyimidacloprid and olefin, two metabolites having toxicity close to that of imidacloprid ${ }^{7}$ increase in the bee during the initial $20 \mathrm{~min}$ of imidacloprid intoxication. However, they are in low amounts compared with imidacloprid and present a peak value $4 \mathrm{~h}$

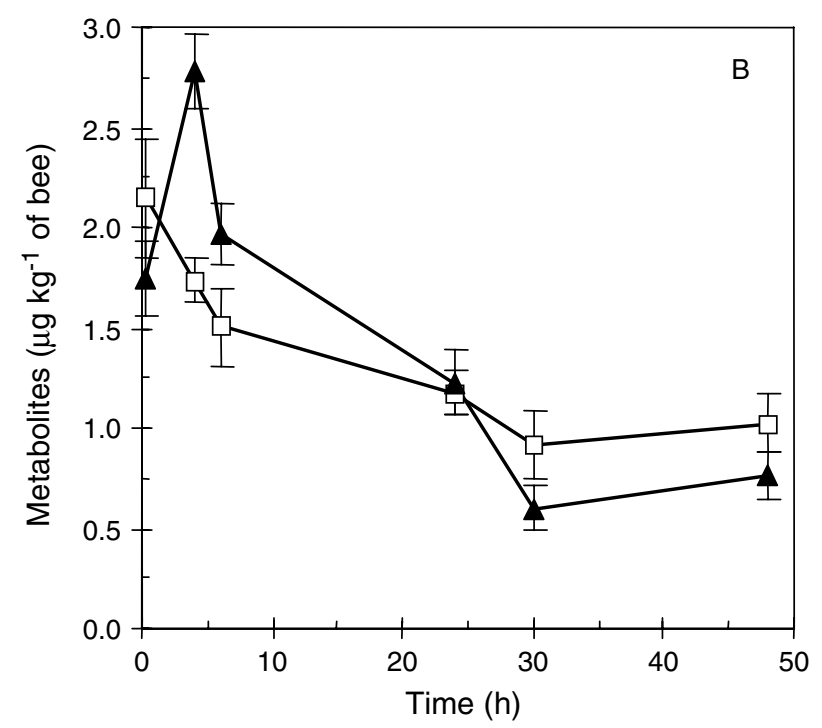

Figure 3. Biotransformation kinetics of imidacloprid after oral exposure to $20 \mu \mathrm{g} \mathrm{kg}^{-1}$ bee. A: Imidacloprid degradation. B: Appearance of $(\square)$ 5-hydroxyimidacloprid and $(\boldsymbol{\Delta})$ olefin. Data represent the means of three experiments performed in triplicate $\pm \mathrm{SD}$.

after intoxication, when imidacloprid has drastically decreased. This suggests that the early neurotoxicity symptoms are induced preferentially by imidacloprid whereas these two toxic metabolites are involved in the bee mortality along with or without residual imidacloprid.

Residue tests performed 20 min after intoxication with the doses of 20 or $50 \mu \mathrm{g}$ per $\mathrm{kg}$ bee showed that imidacloprid can be detected at only $74.5 \%$ and $67 \%$ of the initial dose ingested by the honeybees, respectively. In other words, about $30 \%$ of the residues remained undetected in honeybees. These results imply that either the residue extraction method is not efficient enough or that bees rapidly excrete imidacloprid in its native or metabolised form. It is less probable, however, that the failure to detect $30 \%$ of residues is due to the low efficiency of the extraction method because the yield of this method is about $98 \%$. In addition, this cannot be due to 
the residue excretion by bees because no sign of this was observed 20 min following oral intoxication. Normally, under these experimental conditions, honeybees excrete residues in faeces at least $12 \mathrm{~h}$ after ingestion of active substance. Thus, it is very likely that these $30 \%$ of residues might be imidacloprid metabolites other than 5-hydroxyimidacloprid and olefin. In this case, 5-hydroxyimidacloprid and olefin could not be the major metabolites in the worker bees.

Several methods for the determination of imidacloprid have been published. They involve determination by enzyme-linked immunosorbent assay (ELISA), ${ }^{16,17}$ analysis by liquid chromatography coupled with diodearray detection ${ }^{18}$ or mass spectrometry, ${ }^{19,20}$ and a combination of liquid chromatography and supercritical fluid extraction to increase residue recovery. ${ }^{21}$ However, HPLC-MS/MS is an effective, fast tool for obtaining very useful information on the nature and the quantity of the compounds analysed. This analytical method makes it possible to separate and identify imidacloprid, 5-hydroxyimidacloprid and olefin, and to decrease the limit of quantification (LOQ) of these compounds. This HPLC-MS/MS analytical technique combines sensitivity and selectivity, and allows low LOQ for imidacloprid, 5-hydroxyimidacloprid and olefin even with complex matrices. LOQ depends on sample origin. In sugar beet leaves and roots the limit of detection (LOD) of imidacloprid and its metabolites is $10 \mu \mathrm{g} \mathrm{kg}^{-1}$ fresh weight. ${ }^{22}$ In nectar and beebread, a LOQ of $10 \mu \mathrm{g} \mathrm{kg}^{-1}$ and a LOD of $3 \mu \mathrm{g} \mathrm{kg}^{-1}$ has been reported by Wallner. ${ }^{23}$ In honeybees, this method has given a LOQ of $0.5 \mu \mathrm{g} \mathrm{kg}^{-1}$ for imidacloprid, 5-hydroxyimidacloprid and olefin. Hence, the LOQ obtained for imidacloprid and its two toxic metabolites makes it possible to study metabolism at doses close to the sub-lethal level so as to understand the mode of action.

The present study showed that honeybees are able to rapidly metabolise imidacloprid through a process that reduces exposure to the parent compound and, in most of cases, its toxicity. However, the appearance of 5-hydroxyimidacloprid and olefin, two metabolites toxic at low doses in chronic exposure and at higher doses in acute exposure, coincides with the appearance of mortality induced after acute oral intoxication by imidacloprid. These results strongly suggest that 5-hydroxyimidacloprid and/or olefin contribute to extending the action of imidacloprid in honeybees. Moreover, this study also suggests the existence of other imidacloprid metabolites. It would be interesting to characterise all imidacloprid metabolites in honeybees after oral intoxication by imidacloprid to obtain the whole metabolic profile. Furthermore, locating all the residues in different compartments of honeybees could help us to understand the mode of action of imidacloprid by correlating the pharmacokinetics and the pharmacodynamics of imidacloprid in honeybees.

\section{ACKNOWLEDGEMENTS}

We thank the team of Dr F Placke in Bayer AG Germany for their valuable advice and discussion, and Mr R Schöning and Mrs Gnielka for their technical assistance. This work was supported in part by a CIFRE agreement between INRA and Bayer France.

\section{REFERENCES}

1 Kagabu S, Chloronicotinyl insecticides-discovery, application and future perspective. Rev Toxicol 1:75-129 (1997).

2 Liu MY and Casida JE, High affinity binding of $\left[{ }^{3} \mathrm{H}\right]$ imidacloprid in the insect acetylcholine receptor. Pestic Biochem Physiol 46:40-46 (1993).

3 Nauen R, Ebbinghaus-Kintscher U, Elbert A, Jeschke P and Tietjen K, Acetylcholine receptors as sites for developing neonicotinoid insecticides, in Biochemical sites important in insecticide action and resistance, ed by Ishaaya I, Springer Verlag, Berlin, pp 77-105 (2001).

4 Yamamoto I, Tomizawa M, Saito T, Miyamoto T, Walcott EC and Sumikawa K, Structural factors contributing to insecticidal and selective actions of neonicotinoids. Arch Ins Biochem Physiol 37:24-32 (1998).

5 Tomizawa $M$ and Casida JE, Selective toxicity of neonicotinoids attributable to specificity of insect and mammalian nicotinic receptors. Annu Rev Entomol 48:339-364 (2003).

6 Suchail S, Guez D and Belzunces LP, Characteristics of imidacloprid toxicity in two Apis mellifera subspecies. Environ Toxicol Chem 19:1901-1905 (2000).

7 Suchail S, Guez D and Belzunces LP, Discrepancy between acute and chronic toxicity induced by imidacloprid and its metabolites in Apis mellifera. Environ Toxicol Chem 20:2482-2486 (2001).

8 Schmuck R, Schöning R, Stork A and Schramel O, Risk posed to honeybees (Apis mellifera L, Hymenoptera) by an imidacloprid seed dressing of sunflowers. Pest Manag Sci 57:225-238 (2001).

9 Schmuck R, No causal relationship between Gaucho seed dressing in sunflowers and the French bee malady. Pflanzenschutz Nachrichten Bayer 52:267-309 (1999).

10 Nauen R, Ebbinghaus-Kintscher U and Schmuck R, Toxicity and nicotinic acetylcholine receptor interaction of imidacloprid and its metabolites in Apis mellifera (Hymenoptera: Apidae). Pest Manag Sci 57:577-586 (2001).

11 Nauen R, Tietjen K, Wagner K and Elbert A, Efficacy of plant metabolites of imidacloprid against Myzus persicae and Aphis gossypii (Homoptera: Aphididae). Pestic Sci 52:53-57 (1998).

12 Nauen R, Reckmann U, Armborst S, Stupp HP and Elbert A, Whitefly-active metabolites of imidacloprid: biological efficacy and translocation in cotton plants. Pestic Sci 55:265-271 (1999).

13 Fiedler L, Assessment of chronic toxicity of selected insecticides to honeybees. F Apic Res 26:115-122 (1987).

14 Guez D, Suchail S, Maleszka R, Gauthier M and Belzunces LP, Contrasting effects of imidacloprid on habituation in 7day and 8-day old honeybees. Neurobiol Learn Memory 76:183-191 (2001).

15 EPPO, Guideline on test methods for evaluating the sideeffects of plant protection products on honeybees. Bulletin OEPP/EPPO Bulletin 22:203-215 (1992).

$16 \mathrm{Li} \mathrm{K}$ and Li QX, Development of an enzyme-linked immunosorbent assay for the insecticide imidacloprid. 7 Agric Food Chem 48:3378-8332 (2000).

17 Lee JK, Ahn KC, Park OS, Kang SY and Hammock BD, Development of an ELISA for the detection of the residues of the insecticide imidacloprid in agricultural and environmental samples. F Agric Food Chem 49:2159-2167 (2001).

18 Fernandez-Alba AR, Valverde A, Aguera A, Contreras M and Chiron S, Determination of imidacloprid in vegetables by high-performance liquid chromatography with diode-array detection. f Chromatogr A 721:97-105 (1996). 
19 Fernandez-Alba AR, Tejedor A, Aguera A, Contreras M and Garrido J, Determination of imidacloprid and benzimidazole residues in fruits and vegetables by liquid chromatographymass spectrometry after ethyl acetate multiresidue extraction. f AOAC Internat 83:748-755 (2000).

20 Pous X, Ruiz MJ, Pico Y and Font G, Determination of imidacloprid, metalaxyl, myclobutanil, propham, and thiabendazole in fruits and vegetables by liquid chromatographyatmospheric pressure chemical ionization-mass spectrometry. Fresenius f Anal Chem 371:182-189 (2001).
21 Eskilsson CS and Mathiasson L, Supercritical fluid extraction of the pesticides carbosulfan and imidacloprid from process dust waste. F Agric Food Chem 48:5159-5164 (2000).

22 Rouchaud J, Gustin F and Wauters A, Imidacloprid insecticide soil metabolism in sugar beet field crops. Bull Environ Cont Toxicol 56:29-36 (1996).

23 Wallner K, Tests regarding effects of imidacloprid on honey bees, in Hazard of pesticides to bees, INRA Editions, Paris, pp 91-93 (2001). 